\title{
OPEN Kidney biopsy-based epidemiologic analysis shows growing biopsy rate among the elderly
}

Adél Molnár ${ }^{1}$, Mbuotidem Jeremiah Thomas ${ }^{2}$, Attila Fintha ${ }^{3}$, Magdolna Kardos ${ }^{3}$, Deján Dobi ${ }^{3}$ András Tislér ${ }^{1} \&$ Nóra Ledó ${ }^{1 \bowtie}$

Systematic registration and examination of biopsy-related data in Central and Eastern Europe are scarce, while the health condition of the population is worse compared to other more developed countries. We aim to create a database and analyze the distribution and temporal variation of the renal biopsy diagnoses in Hungary, including the effect of the recent coronavirus pandemic. The diagnoses were standardized according to the recommendation of the European Renal Association. Native biopsy samples processed between January 1, 2006, and December 31, 2020, were analyzed. During the 15 years, 2140 native kidney biopsies were performed. The number of samples increased from 24.5 to 57.9 per million person-years and the median age from 37 to 51 years $(p<0.0001)$. The predominance of glomerular diseases was stable. The most frequent glomerulopathy was $\lg \mathrm{A}$ nephropathy (21.5\%), followed by focal segmental glomerulosclerosis (17.7\%), and membranous nephropathy (15.7\%). Trends showed the rise of ANCA-associated vasculitis. During the coronavirus pandemic, there was a decrease in the number of kidney biopsies and the proportion of membranous nephropathies. The diagnostic trends in our database showed increasing biopsy rates among the elderly and the growing frequencies of age-related diseases, which emphasizes the importance of altering medical focus according to demographic changes in this area.

Percutaneous kidney biopsy is a valuable method in diagnosing certain kidney diseases ${ }^{1}$. Analysis of the biopsy specimens provides information on the pathogenesis, disease activity and facilitates therapeutic decisions.

Current epidemiologic trends on the incidence and prevalence of renal diseases are available throughout Western Europe collected in large national or regional registries ${ }^{2-7}$. There are some registries published from Central Europe ${ }^{8,9}$, however, there has not been any study published in the English literature about the incidence and prevalence of renal biopsies in Hungary in the last decades.

Our study aimed to assess the temporal trends of the incidence and changing patterns of kidney biopsies based on clinicopathological data in Hungary. The main reason for assuming differences in the renal biopsy-related data in this region compared to Western European countries is the higher rate of diabetes mellitus, malignant and cardiovascular diseases ${ }^{10,11}$. These factors convey the risk of developing certain kidney-related injuries ${ }^{12-14}$ that may become evident by analyzing kidney biopsy data.

Our second objective was to evaluate biopsy rates and diagnoses in 2020 compared to the previous years. The presence of the global coronavirus pandemic may have had an impact on the availability of various diagnostic processes, such as kidney biopsies. The distribution of renal diseases diagnosed by biopsies during the pandemic may give us valuable information on the crucial indications of this diagnostic tool.

\section{Results}

Demographics. Between 2006 and 2020, 2140 native and 111 transplant biopsies were evaluated. The latter ones were excluded from our analysis. The total number of native biopsy diagnoses was 2296 .

The male/female ratio was $49.8 \% / 50.2 \%$, with a mean age of $44.2 \pm 21.9$ years (Table 1 ). The youngest patient was 4 months, while the oldest was 90 years old. The median age was 46 years. $18.3 \%$ of the recorded biopsies were obtained from children, $61.3 \%$ from adults, and $20.4 \%$ from the elderly. The median age increased significantly

${ }^{1}$ Department of Internal Medicine and Oncology, Faculty of Medicine, Semmelweis University, Korányi Sándor utca 2/a, Budapest 1083, Hungary. 'Institute of Translational Medicine, Semmelweis University, Budapest, Hungary. ${ }^{3}$ 2nd Department of Pathology, Faculty of Medicine, Semmelweis University, Budapest, Hungary. ${ }^{\square}$ email: ledo.nora@med.semmelweis-univ.hu 


\begin{tabular}{|l|l|l|l|l|l|l|l|}
\hline Category & All & $\mathbf{2 0 0 6 - 2 0 0 8}$ & $\mathbf{2 0 0 9 - 2 0 1 1}$ & $\mathbf{2 0 1 2 - 2 0 1 4}$ & $\mathbf{2 0 1 5 - 2 0 1 7}$ & $\mathbf{2 0 1 8 - 2 0 2 0}$ & $\boldsymbol{p}$ \\
\hline Age (years) & $\begin{array}{l}44.2 \pm 21.9(46 ; \\
0.25-90)\end{array}$ & $37.8 \pm 22.7(37 ; 0.8-89)$ & $\begin{array}{l}37.5 \pm 23.2(38 ; \\
0.25-81)\end{array}$ & $38.7 \pm 22.4(40 ; 3-80)$ & $\begin{array}{l}47.5 \pm 20.5(49 ; \\
0.75-88)\end{array}$ & $49.0 \pm 19.9(51 ; 2-90)$ & $<0.0001$ \\
\hline Gender $(\mathrm{m} / \mathrm{f})$ & $1065(49.8) / 1075(50.2)$ & $144(49.0) / 150(51.0)$ & $145(49.2) / 150(50.8)$ & $146(53.9) / 125(46.1)$ & $304(49.0) / 316(51.0)$ & $326(49.4) / 334(50.6)$ & NS \\
\hline Children $(\leq 18$ y) & $391(18.3)$ & $81(27.6)$ & $92(31.2)$ & $74(27.3)$ & $73(11.8)$ & $71(10.8)$ & $<0.0001$ \\
\hline Adult $(19-65$ y) & $1312(61.3)$ & $172(58.5)$ & $161(54.6)$ & $154(56.8)$ & $400(64.5)$ & $425(64.4)$ & $<0.0001$ \\
\hline Elderly $(\geq 66$ y) & $437(20.4)$ & $41(13.9)$ & $42(14.2)$ & $43(15.9)$ & $147(23.7)$ & $164(24.8)$ & $<0.0001$ \\
\hline Biopsy rate (pmp) & 36.3 & 24.5 & 24.2 & 22.3 & 55.2 & 57.9 & \\
\hline
\end{tabular}

Table 1. Demographics. The age of the patients is presented as mean \pm SD (median; range); the gender and the age group are presented as the patient number with the percentage (\%). $p$ values show the result of the statistical analysis of the difference between the 3-year intervals. Kruskal-Wallis test (age) or Chi-square test were used (gender, age groups), accordingly. $N S$ nonsignificant, $m$ male, $f$ female, $y$ year, $p m p$ per million person-years.

\begin{tabular}{|l|l|l|l|l|l|l|l|l|}
\hline \multirow{2}{*}{ Category } & All & $\mathbf{2 0 0 6 - 2 0 0 8}$ & $\mathbf{2 0 0 9 - 2 0 1 1}$ & $\mathbf{2 0 1 2 - 2 0 1 4}$ & $\mathbf{2 0 1 5 - 2 0 1 7}$ & $\mathbf{2 0 1 8 - 2 0 2 0}$ & & \multirow{2}{*}{} \\
\cline { 2 - 8 } GD & $\mathbf{n = 2 2 9 6}$ & $\mathbf{n = 3 3 1}$ & $\mathbf{n = 3 2 7}$ & $\mathbf{n = 2 8 8}$ & $\mathbf{n = 6 7 8}$ & $\mathbf{n = 6 7 2}$ & $\boldsymbol{p}$ & $\boldsymbol{p}^{*}$ \\
\hline TID & $1499(65.3)$ & $205(61.9)$ & $204(62.4)$ & $189(65.6)$ & $445(65.6)$ & $456(67.9)$ & NS & NS \\
\hline DM & $192(8.4)$ & $44(13.3)$ & $33(10.1)$ & $25(8.7)$ & $51(7.5)$ & $39(5.8)$ & 0.001 & 0.007 \\
\hline HT/RV & $141(6.1)$ & $15(4.5)$ & $17(5.2)$ & $18(6.3)$ & $44(6.5)$ & $47(7.0)$ & NS & NS \\
\hline OSD & $106(4.6)$ & $17(5.1)$ & $16(4.9)$ & $5(1.7)$ & $48(7.1)$ & $20(3.0)$ & 0.001 & 0.009 \\
\hline FHN & $109(4.7)$ & $5(1.5)$ & $16(4.9)$ & $17(5.9)$ & $31(4.6)$ & $40(6.0)$ & NS & NS \\
\hline MISC & $67(2.9)$ & $18(5.4)$ & $15(4.6)$ & $14(4.9)$ & $8(1.2)$ & $12(1.8)$ & $<0.0001$ & 0.02 \\
\hline
\end{tabular}

Table 2. Frequency of the main renal diagnostic categories in the specified periods. The table shows the frequencies of the main diagnostic groups. They are presented as absolute numbers and percentages (\%). $p$ values show the result of the statistical analysis of the difference between the 3-year intervals. $p^{*}$ values demonstrate the difference between the last 3 years (2018-2020) and the first 12 years (2006-2017). Chisquare test was used. GD glomerular diseases, TID tubulointerstitial diseases, $D M$ diabetes mellitus, $H T / R V$ hypertension/renal vascular disease, OSD other systemic disease affecting the kidney, FHN familial/hereditary nephropathies, MISC miscellaneous diseases, NS nonsignificant.

$(p<0.0001)$ in the last 6 years $(2015-2020)$, and the proportion of the patients above 18 years increased as well $(p<0.0001)$ (Table 1$)$.

There were no significant changes in the gender distribution during this period. The biopsy rate increased in the last 6 years (2015-2020); the average rate was 36.3 per one million person-years in 15 years (Table 1). The average gender-based rate was 38.2 and 34.6 per one million person-years (males and females, respectively).

Frequencies of the main disease groups. Overall, the biopsies had glomerular diseases (GD) with $65.3 \%$, followed by tubulointerstitial diseases (TID, 8.4\%), diabetes mellitus (DM, 6.1\%), other systemic diseases (OSD, 4.7\%), renal vascular diseases (HT/RV, 4.6\%), familial/hereditary nephropathies (FHN, 2.9\%), and miscellaneous (MISC, 7.9\%) diagnoses. (Table 2, Fig. 1a).

The group of glomerular diseases encompassed a wide range of diagnoses of different etiology, which we analyzed separately, and present the findings in this article later.

The group of tubulointerstitial disease $(n=192)$ comprised primarily of drug-induced tubulointerstitial nephritis $(n=176,91.7 \%)$, but we encountered also autoimmune mechanism $(n=7,3.6 \%)$, calcium $(n=4,2.1 \%)$ and uric acid deposition diseases $(n=2,1 \%)$, and HIV nephropathy $(n=3,1.6 \%)$. The group of other systemic diseases $(n=109)$ comprised of amyloidosis $(n=90,82.6 \%)$ and thrombotic microangiopathy $(n=19,17.4 \%)$. In the familial/hereditary nephropathy group $(n=67)$, we found Alport-syndrome $(n=13,19.4 \%)$, thin basement membrane disease $(n=46,68.7 \%)$, nephronophthisis $(n=2,3 \%)$, primary hyperoxaluria $(n=4,6 \%)$, and genetically proven congenital thrombotic microangiopathy $(n=2,3 \%)$. The miscellaneous group $(n=182)$ assembled chronic kidney failure of unknown etiology $(n=48,26.4 \%)$, acute pyelonephritis $(n=5,2.7 \%)$, acute kidney injury $(n=32,17.6 \%)$, tumors $(n=5,2.7 \%)$, oligomeganephronia $(n=1,0.5 \%)$, sine morbo diagnoses $(n=8,4.4 \%)$, or specimens that did not have diagnosis due to technical problems $(n=83,45.6 \%)$.

3-year interval trends show dominance of glomerular diseases. For evaluation of the changing patterns over time, we analyzed the trends between 3-year intervals (Table 2).

Glomerular diseases were the most frequent throughout the years without any change in the fraction of total distribution. 
a

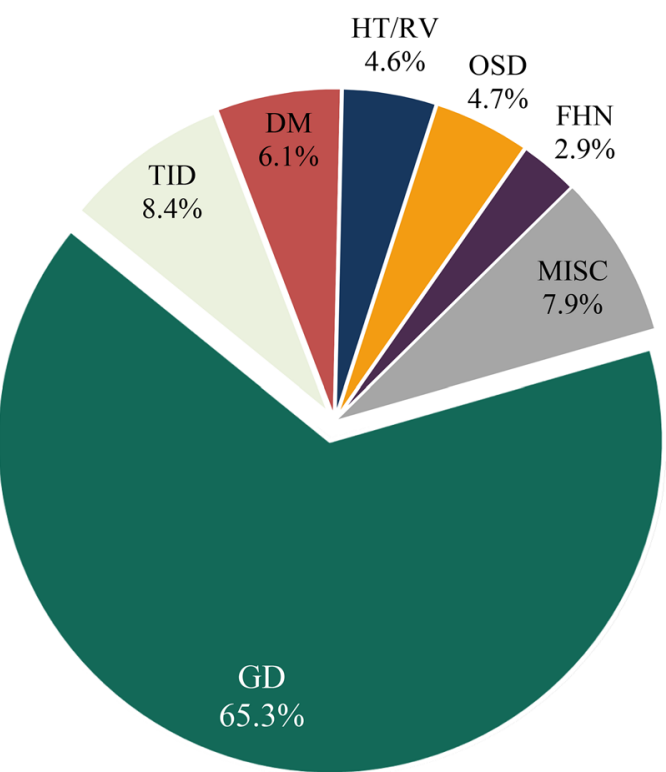

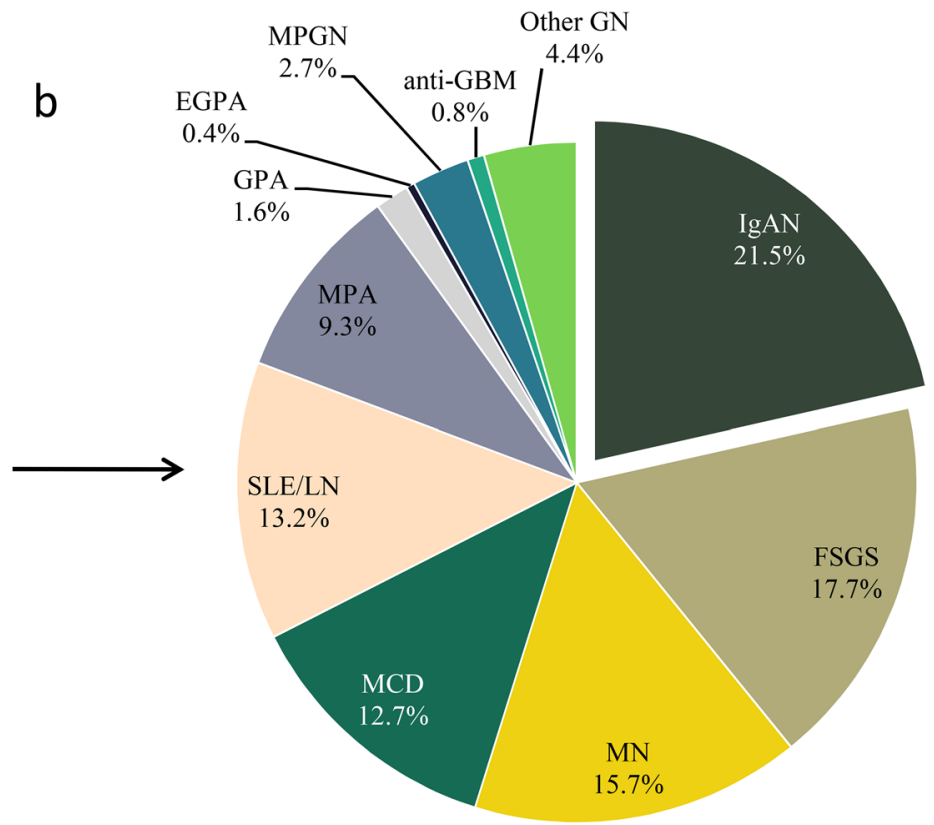

Figure 1. Frequencies of the main groups throughout 15 years (a). GD glomerular diseases, TID tubulointerstitial diseases, $D M$ diabetes mellitus, $H T / R V$ hypertension/renal vascular disease, $O S D$ other systemic disease affecting the kidney, FHN familial/hereditary nephropathies, MISC miscellaneous diseases. Frequencies of glomerular diseases throughout the 15 years (b). IgAN IgA nephropathy-histologically proven and Henoch-Schönlein purpura/nephritis, FSGS focal segmental glomerulosclerosis, $M N$ membranous nephropathy (primary and secondary), $M C D$ minimal change disease, $S L E / L N$ systemic lupus erythematosus/ lupus nephritis, $M P A$ microscopic polyangiitis, GPA granulomatosis with polyangiitis, EGPA eosinophilic granulomatosis with polyangiitis, MPGN membranoproliferative glomerulonephritis, Other GN other glomerulonephritis.

\begin{tabular}{|c|c|c|c|c|c|c|c|}
\hline \multirow[b]{2}{*}{ Category } & \multicolumn{7}{|c|}{$2006-2020$} \\
\hline & $\begin{array}{l}\text { Male } \\
n=1161\end{array}$ & $\begin{array}{l}\text { Female } \\
n=1135\end{array}$ & $p$ & $\begin{array}{l}\leq 18 y \\
n=412\end{array}$ & $\begin{array}{l}19-65 y \\
n=1416\end{array}$ & $\begin{array}{l}\geq 66 y \\
n=468\end{array}$ & $p$ \\
\hline GD (\%) & 64.3 & 66.3 & NS & 68.4 & 65.8 & 60.9 & NS \\
\hline TID (\%) & 9.3 & 7.4 & NS & 10.7 & 7.8 & 7.9 & NS \\
\hline DM (\%) & 7.1 & 5.1 & 0.025 & 0.7 & 7.3 & 7.3 & $<0.0001$ \\
\hline HT/RV (\%) & 5.3 & 3.9 & NS & 1.0 & 5.4 & 5.6 & $<0.0001$ \\
\hline OSD (\%) & 3.4 & 6.2 & 0.002 & 2.2 & 4.5 & 7.7 & 0.001 \\
\hline FHN (\%) & 2.2 & 3.7 & 0.038 & 11.4 & 1.4 & 0.0 & $<0.0001$ \\
\hline MISC (\%) & 8.4 & 7.4 & NS & 5.6 & 7.7 & 10.7 & 0.012 \\
\hline
\end{tabular}

Table 3. Percentages of the main renal diagnostic categories according to gender and age. The table shows the fraction of total of the main diagnoses according to gender and age. They are presented as percentages (\%). $p$ values show the result of the statistical analysis of the difference between gender or the age groups. Chisquare test was used. GD glomerular diseases, TID tubulointerstitial diseases, $D M$ diabetes mellitus, $H T / R V$ hypertension/renal vascular disease, OSD other systemic disease affecting the kidney, $F H N$ familial/hereditary nephropathies, MISC miscellaneous diseases, NS nonsignificant, $y$ years.

TID decreased in the last three years (2018-2020) $(p=0.007)$, as well as FHN $(p=0.02)$, and HT/RV $(p=0.009)$. The decrease of the FHN diagnoses was strongly affected by the increasing age, while the decrease in HT/RV was independent of the increasing age of the patients. (Suppl. Table 1).

Even though we demonstrated a steady increase in the frequency of DM, it was not statistically significant $(p=0.745)$.

Gender analysis in the main diagnostic categories; males prevail in diabetes mellitus. Among the distribution of the diagnoses, gender plays a significant role $(p=0.0004)$. Glomerular diseases displayed equal distribution between genders. We observed a significantly higher number of males in DM $(p=0.025)$ and significantly more females in the OSD $(p=0.002)$ and the FHN group $(p=0.038)$ (Table 3, Fig. 2a). 


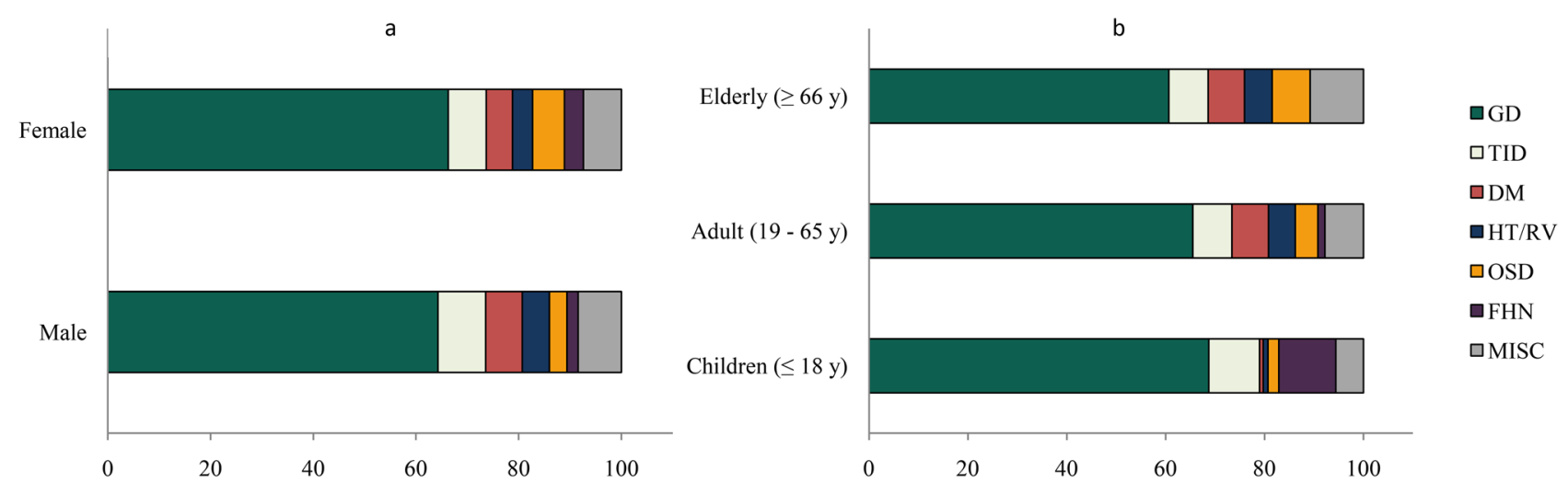

Figure 2. The fraction of total of the main diagnoses according to gender (a) and age groups (b). They are presented percentages (\%). GD glomerular diseases, TID tubulointerstitial diseases, DM diabetes mellitus, $H T / R V$ hypertension/renal vascular disease, OSD other systemic disease affecting the kidney, FHN familial/ hereditary nephropathies, MISC miscellaneous diseases, $y$ years.

Age analysis in the main diagnostic categories. Regarding the age groups, we observed a significant difference in the distribution of the diagnosis between children, adults, and the elderly $(p<0.0001)$.

Glomerular diseases were dominant across all age groups (60.9-68.4\%).

We noticed a higher number of diabetes mellitus $(p<0.0001)$, hypertension/renal vascular $(p<0.0001)$, other systemic diseases $(p=0.001)$, and miscellaneous diagnoses $(p=0.012)$ in the adult and elderly group. As expected, familial/hereditary nephropathies were diagnosed more excessively in children $(p<0.0001)$ (Table 3 , Fig. 2b).

Main diagnostic categories, genders within the age groups. We also adjusted the genders within the age groups over the years.

Examination showed female dominance in the other systemic disease group in adults $(p=0.0045)$ and male dominance in the elderly diabetes mellitus group $(p=0.0312)$ (Suppl. Table 2, Suppl. Fig. 1).

Frequency of glomerular diseases; IgAN is the most frequent glomerulopathy in our database. Since the majority of the specimens were glomerular diseases, we conducted further analysis on this group.

The IgA nephropathy group includes IgA nephropathy and IgA vasculitis (Henoch-Schönlein purpura). The membranous nephropathy group contains both primary and secondary forms. Other glomerulonephritis group collects entities that occurred infrequently in our database: $\operatorname{IgM}$ nephropathy $(n=3)$, diffuse endocapillary glomerulonephritis $(n=41)$, histologically indeterminate glomerulonephritis $(n=15)$, cryoglobulinemia $(n=6)$, and C1q nephropathy $(\mathrm{n}=1)$.

ANCA-associated vasculitis group consisted of microscopic polyangiitis (MPA), granulomatosis with polyangiitis (GPA), and eosinophil granulomatosis with polyangiitis (EGPA).

The most frequent glomerulopathy was IgA nephropathy (IgAN, 21.5\%), followed by focal segmental glomerulosclerosis (FSGS, 17.7\%), membranous nephropathy (MN, 15.7\%), minimal change disease (MCD, 12.7\%), systemic lupus erythematosus with lupus nephritis (SLE/LN, 13.2\%), ANCA-associated vasculitis (11.3\%, with the diagnosis of MPA in 9.3\%), other glomerulonephritis group (4.4\%), membranoproliferative glomerulonephritis (MPGN, 2.7\%) and anti-GBM nephropathy (0.8\%). (Table 4, Fig. 1b).

3-year trends in glomerular diseases indicate a rise of ANCA-associated vasculitis and MPGN. IgAN remained the prevailing diagnosis over the years.

During the 15 -years, we observed a decrease in the biopsy diagnoses of MCD $(p=0.038)$. FSGS also decreased in the last three years $(2018-2020)(p=0.027)$, however, these changes were age-dependent.

ANCA-associated vasculitis showed an increasing frequency in the 15 -year period $(p=0.004)$. Within this group, MPA demonstrated the same trend $(p=0.012)$, while changes for GPA and EGPA were not significant. The increase in MPA diagnoses was partly explained by the increasing age of the patients.

An increase was found in MPGN in the last three years $(2018-2020)(p=0.021)$, which was age and gender independent (Table 4, Suppl. Table 1).

Glomerular diseases and gender: male dominance in MN. The leading diagnoses of males were IgA nephropathy (30.6\%), while lupus nephritis proved to be the most frequent glomerulonephritis (21.8\%) in females.

Analyzing the subgroups, we found a significant male dominance in MN $(p=0.022)$ and $\operatorname{IgAN}(p<0.0001)$, and female dominance in MPA $(p<0.0001)$ and SLE/LN $(p<0.0001)$.

The distribution of MCD, MPG, and anti-GBM was divided between the genders almost equally (Table 5, Fig. 3a). 


\begin{tabular}{|l|l|l|l|l|l|l|l|l|}
\hline \multirow{2}{*}{ Category } & All & $\mathbf{2 0 0 6 - 2 0 0 8}$ & $\mathbf{2 0 0 9 - 2 0 1 1}$ & $\mathbf{2 0 1 2 - 2 0 1 4}$ & $\mathbf{2 0 1 5 - 2 0 1 7}$ & $\mathbf{2 0 1 8 - 2 0 2 0}$ & & \multirow{2}{*}{} \\
\cline { 2 - 8 } & $\mathbf{n}=\mathbf{1 4 9 9}$ & $\mathbf{n = 2 0 5}$ & $\mathbf{n = 2 0 4}$ & $\mathbf{n}=\mathbf{1 8 9}$ & $\mathbf{n = 4 4 5}$ & $\mathbf{n = 4 5 6}$ & $\boldsymbol{p}$ & $\boldsymbol{p}^{*}$ \\
\hline IgAN & $322(21.5)$ & $48(23.4)$ & $47(23.0)$ & $42(22.2)$ & $84(18.9)$ & $101(22.1)$ & NS & NS \\
\hline FSGS & $265(17.7)$ & $44(21.5)$ & $41(20.1)$ & $38(20.1)$ & $77(17.3)$ & $65(14.3)$ & NS & 0.027 \\
\hline MN & $235(15.7)$ & $32(15.6)$ & $25(12.3)$ & $26(13.8)$ & $77(17.3)$ & $75(16.4)$ & NS & NS \\
\hline MCD & $190(12.7)$ & $30(14.6)$ & $35(17.2)$ & $24(12.7)$ & $60(13.5)$ & $41(9.0)$ & 0.038 & 0.004 \\
\hline SLE/LN & $198(13.2)$ & $21(10.2)$ & $25(12.3)$ & $25(13.2)$ & $67(15.1)$ & $60(13.2)$ & NS & NS \\
\hline MPA & $140(9.3)$ & $12(5.9)$ & $14(6.9)$ & $16(8.5)$ & $37(8.3)$ & $61(13.4)$ & 0.012 & $<0.001$ \\
\hline GPA & $24(1.6)$ & $2(1.0)$ & $5(2.5)$ & $3(1.6)$ & $4(0.9)$ & $10(2.2)$ & NS & NS \\
\hline EGPA & $6(0.4)$ & - & - & $1(0.5)$ & $2(0.4)$ & $3(0.7)$ & NS & NS \\
\hline MPGN & $41(2.7)$ & $2(1.0)$ & $6(2.9)$ & $4(2.1)$ & $10(2.2)$ & $19(4.2)$ & NS & 0.021 \\
\hline Anti-GBM & $12(0.8)$ & $2(1.0)$ & $1(0.5)$ & $2(1.1)$ & $3(0.7)$ & $4(0.9)$ & NS & NS \\
\hline Other GN & $66(4.4)$ & $12(5.9)$ & $5(2.5)$ & $8(4.2)$ & $24(5.4)$ & $17(3.7)$ & NS & NS \\
\hline
\end{tabular}

Table 4. Frequencies of glomerular diseases reported in the specified periods. The table shows the frequencies of glomerular diseases. They are presented as absolute numbers and percentages (\%). $p$ values show the result of the statistical analysis of the difference between the 3 -year intervals. $p^{*}$ values demonstrate the difference between the last 3 years (2018-2020) and the first 12 years (2006-2017). Chi-square test was used. IgAN IgA nephropathy-histologically proven and Henoch-Schönlein purpura/nephritis, FSGS focal segmental glomerulosclerosis, $M N$ membranous nephropathy (primary and secondary), $M C D$ minimal change disease, $S L E / L N$ systemic lupus erythematosus/lupus nephritis, MPA microscopic polyangiitis, GPA granulomatosis with polyangiitis, EGPA eosinophilic granulomatosis with polyangiitis, MPGN membranoproliferative glomerulonephritis, Other GN other glomerulonephritis, NS nonsignificant.

\begin{tabular}{|c|c|c|c|c|c|c|c|}
\hline \multirow[b]{2}{*}{ Category } & \multicolumn{7}{|c|}{$2006-2020$} \\
\hline & $\begin{array}{l}\text { Male } \\
n=746\end{array}$ & $\begin{array}{l}\text { Female } \\
\mathrm{n}=753\end{array}$ & $p$ & $\begin{array}{l}\leq 18 y \\
n=282\end{array}$ & $\begin{array}{l}19-65 y \\
n=932\end{array}$ & $\begin{array}{l}\geq 66 y \\
n=285\end{array}$ & $p$ \\
\hline $\operatorname{IgAN}(\%)$ & 30.6 & 12.5 & $<0.0001$ & 30.5 & 22.3 & 9.8 & $<0.0001$ \\
\hline FSGS (\%) & 16.8 & 18.6 & NS & 25.2 & 17.3 & 11.6 & 0.001 \\
\hline MN (\%) & 18.0 & 13.4 & 0.022 & 2.8 & 14.5 & 32.3 & $<0.0001$ \\
\hline MCD (\%) & 12.5 & 12.9 & NS & 19.9 & 11.9 & 8.1 & $<0.0001$ \\
\hline SLE/LN (\%) & 4.6 & 21.8 & $<0.0001$ & 8.2 & 18.0 & 2.5 & $<0.0001$ \\
\hline MPA (\%) & 6.6 & 12.1 & $<0.0001$ & 3.5 & 7.4 & 21.4 & $<0.0001$ \\
\hline GPA (\%) & 2.0 & 1.2 & NS & 1.8 & 1.3 & 2.5 & NS \\
\hline EGPA (\%) & 0.3 & 0.5 & NS & - & 0.2 & 1.4 & 0.017 \\
\hline MPGN (\%) & 2.9 & 2.5 & NS & 3.9 & 2.5 & 2.5 & NS \\
\hline Anti-GBM (\%) & 0.8 & 0.8 & NS & 1.1 & 0.6 & 1.1 & NS \\
\hline Other GN (\%) & 5.1 & 3.7 & NS & 3.2 & 4.0 & 7.0 & NS \\
\hline
\end{tabular}

Table 5. Percentages of the glomerular diseases according to gender and age. The table shows the fraction of total of the glomerular diseases according to gender and age. They are presented as percentages (\%). $p$ values show the result of the statistical analysis of the difference between the genders or age groups. Chi-square test was used. IgAN IgA nephropathy-histologically proven and Henoch-Schönlein purpura/nephritis, FSGS focal segmental glomerulosclerosis, $M N$ membranous nephropathy (primary and secondary), $M C D$ minimal change disease, $S L E / L N$ systemic lupus erythematosus/lupus nephritis, MPA microscopic polyangiitis, $G P A$ granulomatosis with polyangiitis, EGPA eosinophilic granulomatosis with polyangiitis, MPGN membranoproliferative glomerulonephritis, Other GN other glomerulonephritis, NS nonsignificant, $y$ years.

Glomerular diseases and age groups: MN dominate in the elderly. IgAN was the most frequent glomerulonephritis in the children and adults, while MN topped the elderly (32.3\%) group.

Within the age groups, we noticed an adult/elderly dominance in $\mathrm{MN}(p<0.0001)$, MPA $(p<0.001)$, and in EGPA $(p=0.017)$.

On the contrary, SLE/LN demonstrated children/adult dominance $(p<0.0001)$.

MCD $(p<0.0001)$, FSGS $(p=0.001)$, and IgAN $(p<0.0001)$ proved to be the most prevalent in children.

Although MPGN was higher in children, and there were more GPA in the elderly, these differences were not significant (Table 5, Fig. 3b).

Glomerular diseases; genders within age groups. Furthermore, we broke down the glomerular diagnoses based on gender within the age groups. 
$\mathbf{a}$

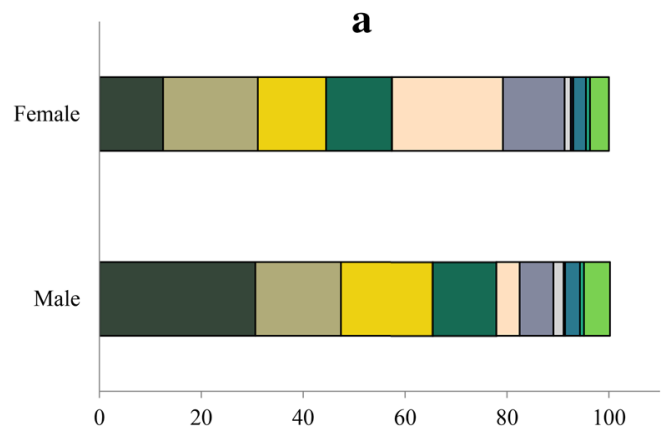

b

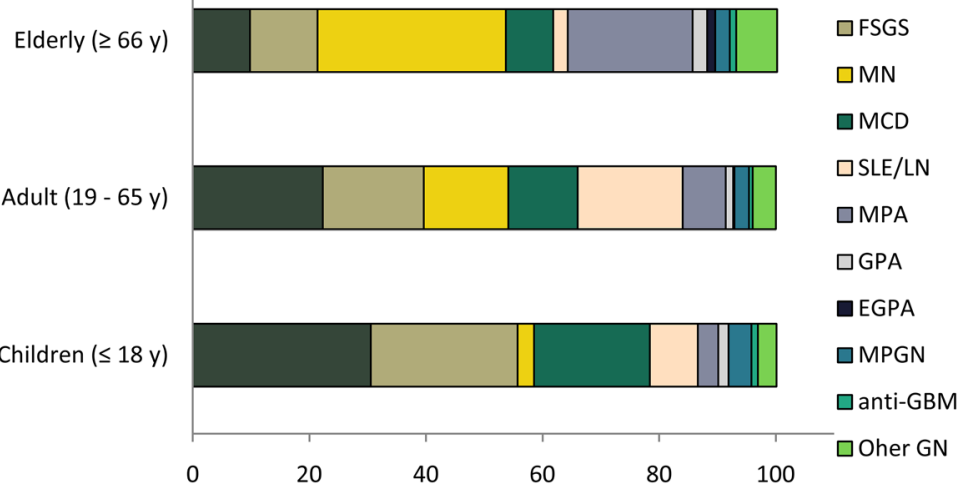

Figure 3. The fraction of total of the glomerular diseases according to gender (a) and age groups (b). They are presented as percentages (\%). IgAN IgA nephropathy-histologically proven and Henoch-Schönlein purpura/ nephritis, FSGS focal segmental glomerulosclerosis, $M N$ membranous nephropathy (primary and secondary), $M C D$ minimal change disease, SLE/LN systemic lupus erythematosus/lupus nephritis, MPA microscopic polyangiitis, GPA granulomatosis with polyangiitis, EGPA eosinophilic granulomatosis with polyangiitis, $M P G N$ membranoproliferative glomerulonephritis, Other GN other glomerulonephritis, $y$ years.

A significant male dominance in IgAN in each age groups $(p<0.0001$ children, $p<0.0001$ adults, $p=0.015$ elderly) and a female predominance in SLE/LN ( $p<0.0001$ children, $p<0.0001$ adults, $p=0.018$ elderly) were observed. Additionally, we observed a female predominance in children's group in MPA $(p=0.019)$, and male dominance in $\mathrm{MN}(p=0.001)$ among adults (Suppl. Table 3, Suppl. Fig. 2).

Additional findings and rare diseases. Further analysis demonstrated a female dominance in amyloidosis $(p=0.026)$, especially in the AA (Amyloid A) amyloidosis group $(p=0.008)$.

During the years, we discovered a significant change in the distribution of light chain deposition disease (LCDD, $p<0.0001$ ). LCDD increased significantly in the last 3-year period, which was partly explained by the increasing age (Suppl. Table 1).

During these 15 years, we encountered some rarities: three IgM nephropathies, one C1q nephropathy, three HIV nephropathies, and five immunotactoid glomerulopathies.

Coronavirus pandemic affected the frequencies of kidney biopsies and the histopathologic diagnoses. In 2020, there was a decrease in the number of kidney biopsies compared to the average of the previous three years (2017-2019): 161 biopsies, 43.4 per one million person-years vs. 242.3 biopsies per year, 64.2 per one million person-year between 2017 and 2019. Among the biopsy diagnoses, we found a decrease in membranous nephropathy (10 in $161(6.2 \%)$ in 2020 vs. 86 in $727(11.8 \%)$ between 2017 and 2019, $p=0.038$ ), an increase in GPA (6 in 727 (0.8\%) between 2017 and 2019 vs. 5 in $161(3.1 \%)$ in 2020, $p=0.018$ ), other GN (14 in 727 (1.9\%) between 2017 and 2019 vs. 9 in 161 (5.6\%) in 2020, $p=0.008)$, and miscellaneous diseases (55 in 727 (7.6\% between 2017 and 2019 vs. 22 in 161 (13.7\%) in 2020, $p=0.013$ ) (Fig. 4).

\section{Discussion}

Our 15-year retrospective study of renal biopsies provides comprehensive data about demographics and the prevalence of kidney diseases in Hungary. Although our report was conducted in a single pathological center, it covers almost half of the Hungarian population and can therefore be generalized.

Our database has a slight female dominance, which might root in the fact that the male/female demographic ratio decreases with the increase of age ${ }^{15}$. However, the gender-based biopsy rate showed a relatively higher number of males who have gone under renal biopsy. This compares well with other European studies ${ }^{1}$.

The mean age was $44.2 \pm 21.9$ years, which coincides with similar reports in other registries so far ${ }^{1}$. The increase in biopsy samples from 2014 was partly due to the addition of other tertiary nephrology centers to the catchment area but the contribution of the increasingly aging population and subsequent higher biopsy rate in the elderly population cannot be disregarded either. This implies that there is a long-term outlook even for senior patients, and suggests an increasing life expectancy, giving an indirect hint of improving health care and social conditions ${ }^{16}$.

The average biopsy rate of 36.3 per one million person-years lags behind most of the European reports ${ }^{17}$, however, from 2015, our data collection rate has increased significantly and seems to be catching up. We assume many reasons behind the lower rates. First, the catchment area is scattered, and there are just a few hospitals that maintain a regular connection with the university pathological department. In addition, a conservative approach to biopsies may have caused the lower number of biopsy incidences. Financial considerations can also hold the biopsy rates back ${ }^{1,9}$. Nevertheless, biopsy rates in Hungary have significantly improved over the last few years. This may be due to several reasons. The decision to biopsy has been positively impacted by the increased proficiency and low complication rates of the procedure. This has resulted in increased ease of performing renal biopsy procedures by nephrologists and subsequently has led to improved biopsy skills. Additionally, nephrologists with 
$\mathrm{n}=727$

(241.3/Year)

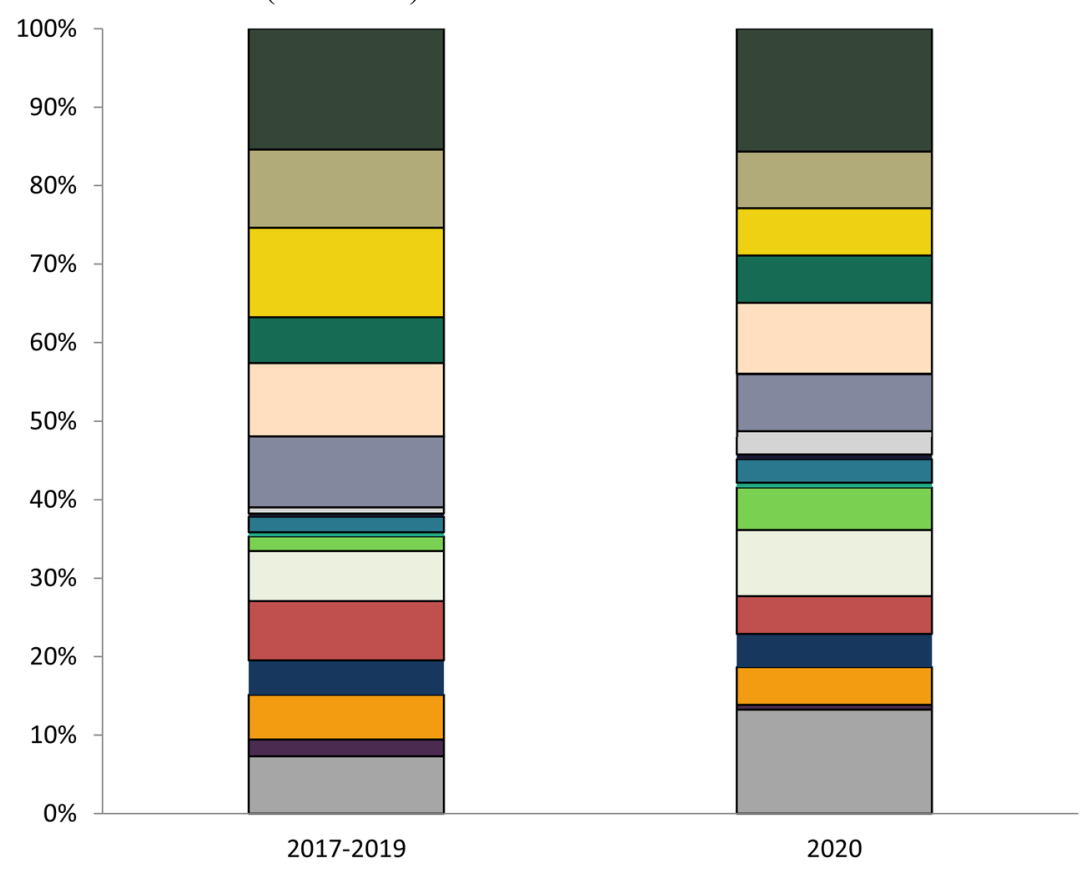

口IgAN

口FSGS

$\square \mathrm{MN}$

$\square M C D$

口SLE/LN

口MPA

口GPA

- EGPA

$\square M P G N$

anti-GBM

口Other GN

$\square$ TID

口DM

- HT/RV

口OSD

$\square \mathrm{FHN}$

口MISC

Figure 4. Coronavirus pandemic affected the frequencies of kidney biopsies and the histopathologic diagnoses. IgAN IgA nephropathy-histologically proven and Henoch-Schönlein purpura/nephritis, FSGS focal segmental glomerulosclerosis, $M N$ membranous nephropathy (primary and secondary), $M C D$ minimal change disease, $S L E / L N$ systemic lupus erythematosus/lupus nephritis, $M P A$ microscopic polyangiitis, GPA granulomatosis with polyangiitis, EGPA eosinophilic granulomatosis with polyangiitis, MPGN membranoproliferative glomerulonephritis, Other GN other glomerulonephritis. GD glomerular diseases, TID tubulointerstitial diseases, $D M$ diabetes mellitus, $H T / R V$ hypertension/renal vascular disease, $O S D$ other systemic disease affecting the kidney, FHN familial/hereditary nephropathies, MISC miscellaneous diseases.

higher expertise in performing renal biopsies, tend to have lower threshold for performing these procedures. Furthermore, nephrologists and associated professionals who feel more confident in their fellows' competence are more likely to request more biopsies. The changing emphasis of performing a biopsy during medical training may also contribute to the increase in the biopsy rates. Training pattern has changed in the last decades, leading to a change in the nephrologist population. Many doctors who have trained abroad and those who have familiarized themselves with renal biopsy procedures during their training, become acquainted with it and are more likely to perform it. Thus, with time the biopsy rate could grow exponentially ${ }^{18}$. The widespread availability of the internet, medical search engines, and journals provide better availability of high-quality, up-to-date information on kidney diseases, and the utility of the biopsy, which also has contributed to the lowering threshold for renal biopsy. Nonetheless, we cannot exclude the real increase in the incidence of kidney diseases as a contributing factor to the increased renal biopsy rates as well as the aging population. With aging, certain kidney diseases and renal manifestations of systemic diseases may occur as they have more time to develop.

The results confirmed that glomerular diseases prevail over the other diagnoses similar to most of the registries $^{3,8,17,19-43}$. Within glomerular diseases, IgA nephropathy was the most common entity, which correlates well with another Hungarian registry in a different region ${ }^{44,45}$ and other registries in different countries $^{2-6,8,9,19-21,29-31,46-58}$. Interestingly, there were some countries, mainly outside of Europe, where membranous nephropathy $22,23,26,38,59,60$ or FSGS/MCD were the most frequently diagnosed ${ }^{24,25,32-35,37,40,43,61-70}$. Membranoproliferative glomerulonephritis prevailed in Africa and mostly in Eastern countries ${ }^{7,27,28,39,43,71-74}$. In some countries, lupus nephritis, diffuse endocapillary glomerulonephritis, IgM nephropathy and familial/hereditary nephropathies dominated the renal biopsies ${ }^{36,41,75-78}$ (Fig. 5). The discrepancy of the most frequent diagnoses indicates not only a different genetic, lifestyle and environmental background but also raises awareness for the heterogeneity of the biopsy indications ${ }^{17}$.

Sine morbo diagnoses are mostly believed to be produced by the inherent problem of the sampling errors, resulting in false-negative samples, however, true negative cases cannot be ruled out either.

The key predictor of biopsy adequacy is the number of glomeruli, which changes depending on the kind of glomerular disease. In general, missing the impaired glomeruli in the sample is $10 \%$ if the bioptic sample includes 10 glomeruli and it drops to $1 \%$ if the sample contains 20 glomeruli. As a result, for an acceptable sample, at least 10 glomeruli are required ${ }^{79}$. This notion is supported by the recent guideline of the Kidney Disease: Improving Global Outcomes (KDIGO) organization on the management of glomerular diseases ${ }^{80}$. In case it is not yielded during the sampling, chances of missing the afflicted part of the kidney increase. 


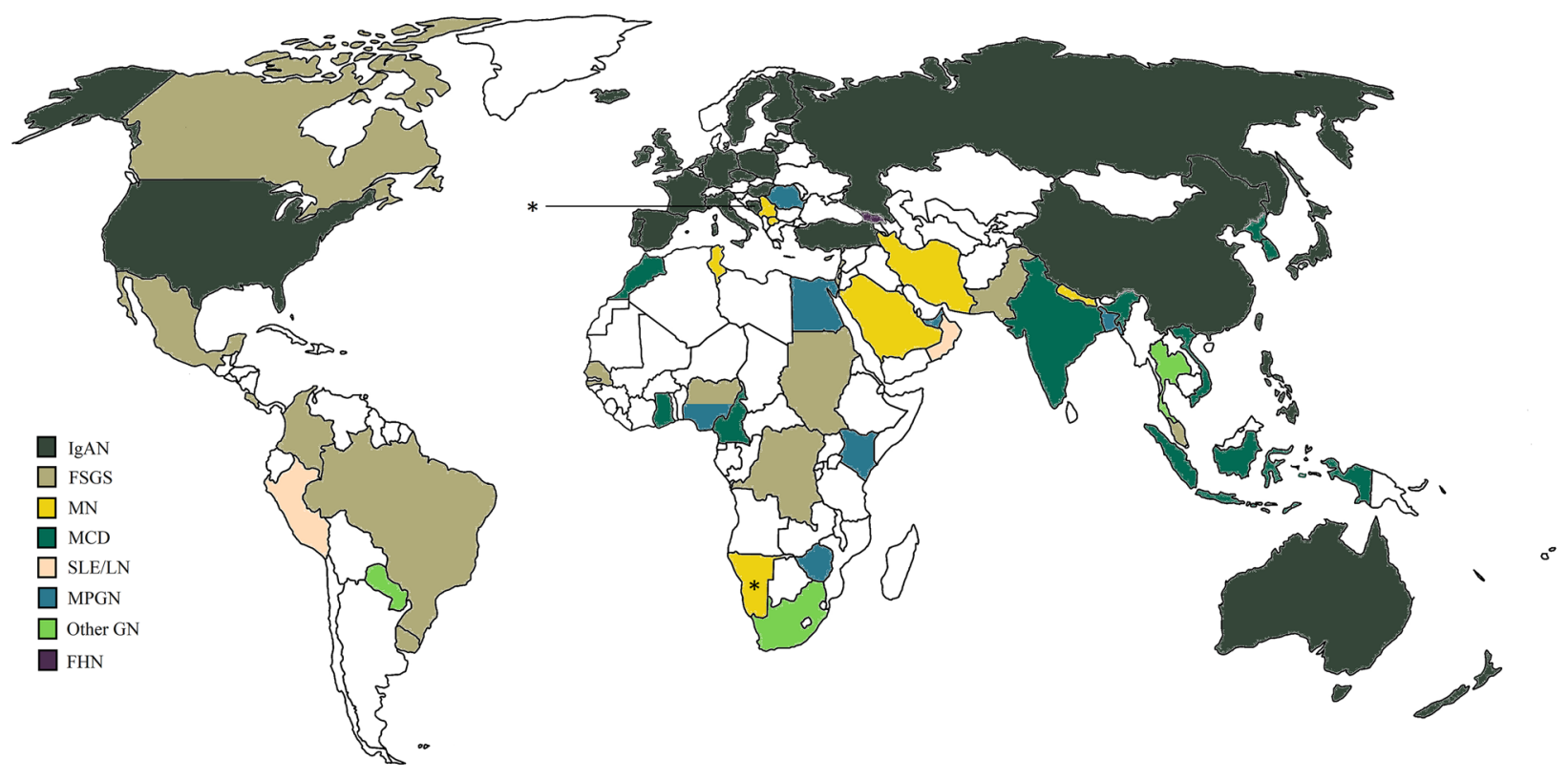

Figure 5. Overview of the most frequent renal diseases in renal registries and studies around the world. Biopsy indication was heterogenous except in Cameroon, Senegal, Ghana, and Zaire, where only nephrotic syndrome was considered. Biopsies were performed on adults \pm children, except Namibia, where only children were enrolled in the study. Information was not found from countries left white. This Figure was created with Paint software (Microsoft Windows $10 \mathrm{v} 20 \mathrm{H} 2$ ). The world map template was downloaded from https://www. dreamstime.com/royalty-free-stock-images-empty-world-map-image4506299 under Royalty-free license, Dreamstime LLC (Brentwood, TN, US). IgAN IgA nephropathy-histologically proven and Henoch-Schönlein purpura/nephritis, FSGS focal segmental glomerulosclerosis, $M N$ membranous nephropathy (primary and secondary), MCD minimal change disease, SLE/LN systemic lupus erythematosus/lupus nephritis, MPGN membranoproliferative glomerulonephritis, Other GN other glomerulonephritis, FHN familial/hereditary nephropathies, MISC miscellaneous diseases. ${ }^{\star}$ Only children were examined.

In our study, negative cases made up for $0.38 \%$ of the total biopsies. This rate varies between 0.3 and $8.5 \%$ in the international reports $9,22,36,47,48,57,61,70$. A biopsy is still the "gold standard" for the diagnostic evaluation of glomerular diseases and the biopsy should be performed when the value of the information obtained from the biopsy exceeds the risk entailed ${ }^{80}$. Most of the renal biopsy indications (e.g. nephrotic syndrome, acute nephritic syndrome, affected kidney in systemic diseases, etc.) rule out the true negative results, hence these are characteristic for kidney diseases. This can explain the small rate of true negative samples compared to other diagnostic tests. Indications for renal biopsy in the countries where the report on negative samples was available, were generally similar. However, the number of the negative samples increased in direct proportion to the rate of biopsies. This correlation draws attention to the threshold for the execution of a renal biopsy: countries that perform a renal biopsy with more subtle clinical or laboratory abnormalities have a higher biopsy rate and increased number of negative histological results, while countries with low negative sample results and biopsy rate may interpret the indications rather strictly. In addition, local resources are also likely to determine the prevailing practice on performing kidney biopsies ${ }^{80}$.

The prevalence of hypertension increases with age ${ }^{81}$, and renal manifestation may be parallel this tendency. In this study, we found less hypertension/renovascular disease-related diagnosis in the biopsy trends despite the increasing age. This might indicate better medical support and blood pressure control for the patients, even in the elderly. On the other hand, we cannot exclude the dilution effect entirely: the rise of the biopsy rate may have contributed to a relatively lower number of hypertensive/renovascular main diagnosis. Here we must note that many specimens had arterial hyalinosis as a sign of hypertension which was not described as the main diagnosis if it was an indirect result or secondary effect. The hypertension/renal vascular main category represents the specimens if the signs of hypertension were explicit or no other pathognomic lesion was found.

The increase of age was accompanied by a surplus of microscopic polyangiitis, and a lower number of familial diseases. As indicated in other studies, the average age is over 50 years in MPA, indicating a higher prevalence in older patients ${ }^{82}$. The increasing number of LCDD and MPGN in the biopsy trends might be attributed to monoclonal gammopathies, which also rise with the aging population. MPGN, as a heterogeneous range of disorders, is often clinically under-recognized and hence, under-diagnosed ${ }^{83}$. Although monoclonal gammopathies may have a diverse and even distinct morphology, the most common pattern is MPGN ${ }^{84-86}$.

The number of membranous nephropathies showed increase with age and demonstrated a male dominance. This may be explained by the gradually aging population ${ }^{10}$ and the corresponding increase in the incidence of malignancies ${ }^{87}$. This finding correlates well with international studies ${ }^{88}$. Nevertheless, the increasing level of air pollutants cannot be excluded either ${ }^{89}$. We demonstrated a slightly higher proportion of MN cases than in the 
neighboring countries, which may be attributed to our worldwide number one ranking in lung and colorectal cancers and a superior place in ovarian and bladder cancers ${ }^{90}$. We also proved that MN occurs at a younger age in males which may be attributed to their lower participation in screening tests, worse diet, and lifestyle differences ${ }^{91}$. It is also worth noting that the availability of anti-PLA2R (phospholipase-A-2-receptor) titer measurements widened our diagnostic arsenal, and in some situations may lead to a decrease in the biopsy incidence in primary $\mathrm{MN}$ cases $^{92}$.

Younger patients were burdened more by lupus nephritis, IgA nephropathy, minimal change disease, and focal segmental glomerulosclerosis. The relative early manifestation of these diseases suggests the possibility of genetic involvement.

The prevalence of diabetic nephropathy varied in the reviewed articles. Its overall prevalence in this study was higher than in most countries ${ }^{17}$. It is worth noting that the population in Hungary has one of the highest overweight and obesity rates in Europe ${ }^{15}$. On the other hand, a Western German study ${ }^{3}$ showed a 3.6-fold higher rate of diabetic nephropathy in their study. The discrepancies suggest a variance in the indications of biopsy. The relatively low incidence of diabetic nephropathy in our study compared to theirs may be due to the fact that performing a renal biopsy in diabetes mellitus is necessary only when an unexpectedly high rate of proteinuria or renal function decline is present. However, early stages of diabetic nephropathy may present with advanced structural damage despite the fairly normal kidney function ${ }^{93}$. This suggests that approaching biopsy indications with a less restrictive attitude may be advantageous and draws attention to the poor secondary prevention measures in Hungary.

MPA is known to have a rather even gender distribution ${ }^{94}$. According to some reports, it has a slight male predominance ${ }^{95-97}$. However, gross comparison in our study showed a significant female dominance. This cannot be explained only by the shrinking number of males with age, since we observed female dominance in all age groups. It raises attention to the possibility, that although MPA is equal and even a bit more frequent in males, the renal manifestation may be affected by gender, and may occur more often in females.

The female dominance of amyloidosis is associated with the female dominance of AA amyloidosis. Most of the patients with this diagnosis had an underlying rheumatoid arthritis, which is more frequent in females. The rest was associated with inflammatory bowel diseases. AA amyloidosis also reflects the prevalence of chronic inflammatory conditions over time.

Furthermore, in this study, the incidence of ANCA-associated glomerulonephritis increased over time. This trend correlates well with previous reports in other epidemiologic studies ${ }^{98-100}$. ANCA-associated vasculitis is more prevalent in the older population ${ }^{101}$, therefore the aging population could explain its increasing incidence. The increased incidence may also be attributed to an actual increase in incidence, change in classification criteria, and wider availability of diagnostic ANCA serology tests ${ }^{102,103}$. Moreover, increased recognition may be due to increased awareness by the clinicians because of a more thorough education ${ }^{98}$.

Due to the COVID-19 pandemic, the healthcare system had a major challenge worldwide. Accordingly, in 2020 the renal biopsy rate was lower, compared to the previous years. Many Hungarian nephrology departments had to switch to urgent care for patients with COVID-19 from March to May and November to December in 2020 , which reduced the number of biopsies that otherwise could have been performed. In addition, patients with less severe symptoms and stable kidney disease avoided hospital visits due to fear of the coronavirus. We hypothesized that during the pandemic only the portion of kidney diseases with rapid progression or severe symptoms, and for which treatment needed a histopathological confirmation ended up in biopsies. Of course, serology results with these patients were non-contributory. This underlines the diagnostic value and indication for biopsies even in these difficult times. Although our database did not have large case numbers in 2020, we found that the rate of MN decreased significantly. In the primary forms of MN where the anti-PLA2R is present, renal biopsies could be disregarded, especially in a pandemic situation. The rise of GPA can be explained partly by the better awareness of the disease, but the effect of the pandemic cannot be excluded either. More data are needed in the future to explain this trend of the disease.

Many countries run renal biopsy registries to have a more comprehensive insight into epidemiologic data, to improve research possibilities $5,9,20,24,47,49-51,55,61,104$. These registries also contain clinical data which can enhance a more in-depth understanding of the diseases. Recently the Hungarian Society of Nephrology has also established a renal biopsy registry, which will aid to conduct clinicopathological research. To this end with this article, we would also like to take the initiative to develop a high-functioning database and encourage both clinicians and pathologists to take a share of filling an international biopsy registry, which would be very important quality feedback to our overall clinical work.

Our retrospective study presents the long-term trends in kidney diseases diagnosed by renal biopsy in Hungary. The diagnostic trends in our database showed increasing biopsy rates among the elderly and the growing frequencies of age-related diseases. Trends of 2020 showed that the availability of kidney biopsies reduced during the COVID-19 pandemic, but renal biopsy remained an important diagnostic tool even in difficult times.

The establishment of not only national but international kidney biopsy registries should be encouraged and supported by scientific societies, as it is very important to compare these trends internationally, which can help to improve the quality control of nephrology care worldwide.

\section{Methods}

Demographics of kidney biopsy samples. We analyzed renal biopsy specimens retrospectively that were examined at the 2nd Department of Pathology, Semmelweis University, between January 2006 and December 2020 , a period of 15 years. 
Samples arrived from 28 different secondary and tertiary nephrology departments from Northern and Central Hungary from four Hungarian counties, including the capital, Budapest. Centers included both adult and pediatric care facilities.

Population estimates were retrieved from the Hungarian Central Statistical Office. The average population in Hungary between 2006 and 2020 was 9,916,101 persons, while the average population of the catchment area during this time period was 3,932,556 persons. Consequently, the mean background population in the examined area provides $39.7 \%$ of the population in Hungary.

The mean population density in these areas in this period was 107 inhabitants $/ \mathrm{km}^{2}$. This is 1.2 times more than the mean population density of Hungary and 3.19 times more than the European average in this period.

Histological assessment. According to our protocol, all specimens were stained with the same techniques and evaluated systematically by light microscopy, immunofluorescent, and electron microscope. Paraffin-embedded kidney tissue sections for light microscopy were routinely stained with hematoxylin and eosin, periodic-acid Schiff, Masson's trichrome, Congo red, and Jones' methenamine silver stains. For immunofluorescence examination, specimens were labelled with IgG, IgA, IgM, C3c, C4c, C1q, fibrin, kappa chain, and lambda chain conjugated fluorescent dye. If indicated for Alport syndrome, staining for collagen IV alpha 5 chain was also used. Between 2006 and 2019, specimens were assessed individually by two experienced nephropathologists (M.K., A.F.). In 2020, another experienced nephropathologist joined the assessments (D.D.). In most cases, clinical information provided by the attending clinicians aided their work.

All samples were included in our analysis, even sampling errors (e.g., adipose tissue). For the analysis, pathological findings documented in paper or electronic medical records were entered in a Microsoft Excel (version 2016) database. We registered the patients' age, gender, primary, secondary and tertiary diagnosis (if more than one histological features were available), and the institution where the biopsy was performed. Repeated kidney biopsies were marked.

Diagnoses. Terminologies were used as described in the European Renal Association-European Dialysis and Transplant Association (ERA-EDTA) coding system ${ }^{105}$. Based on this nomenclature, we divided the diagnoses into seven large renal diagnostic categories: glomerular diseases, tubulointerstitial diseases, diabetes mellitus, hypertension, other systemic diseases, familial nephropathies, and miscellaneous renal disorders.

Transplant kidney biopsies were excluded from the analysis.

In our tables, we present only those diagnostic categories of the ERA-EDTA coding system, where we had at least one diagnosis during the 15 -year-period.

For better comparison with previous studies, we divided patients by age and sex. Patients 18 years or younger were considered as children, those between 19 and 65 years as adults, and those 66 years or older were considered as elderly.

We also grouped diagnoses in 3-year intervals and examined 2020 separately, to be able to assess the effect of the COVID-19 (coronavirus disease 2019) pandemic on biopsy rates.

Statistical analysis. Data were stored in an Excel (Microsoft, version 2016) database file. Statistical analysis was performed using Excel, GraphPad (GraphPad Prism 9.0.0), and IBM SPSS Statistics 27 software programs. Chi-square and Fisher's exact test were used to compare categorical variables and Kruskal-Wallis test for continuous variables based on the result of the Shapiro-Wilk normality test. We also conducted logistic regression analysis with binary dependent variables.

Categorical variables are expressed as number (percentage), continuous variables as mean \pm standard deviation, and median with range. Two-tailed $p$ values $<0.05$ were considered statistically significant.

All analyses were performed in accordance with relevant guidelines and regulations and informed consent was obtained from all subjects and/or their legal guardian(s) for further analyses at the time point of the biopsies. The study was approved by the Semmelweis University Regional and Institutional Committee of Science and Research Ethics (SE RKEB 225/2018).

Received: 4 September 2021; Accepted: 20 December 2021

Published online: 29 December 2021

\section{References}

1. Fiorentino, M. et al. Renal biopsy in 2015-From epidemiology to evidence-based indications. Am. J. Nephrol. 43, 1-19. https:// doi.org/10.1159/000444026 (2016).

2. Simon, P. et al. Epidemiologic data of primary glomerular diseases in western France. Kidney Int. 66, 905-908. https://doi.org/ 10.1111/j.1523-1755.2004.00834.x (2004).

3. Zink, C. M. et al. Trends of renal diseases in Germany: Review of a regional renal biopsy database from 1990 to 2013 . Clin. Kidney J. 12, 795-800. https://doi.org/10.1093/ckj/sfz023 (2019).

4. Hanko, J. B. et al. The changing pattern of adult primary glomerular disease. Nephrol. Dial. Transplant. 24, 3050-3054. https:// doi.org/10.1093/ndt/gfp254 (2009).

5. McQuarrie, E. P. et al. Centre variation in incidence, indication and diagnosis of adult native renal biopsy in Scotland. Nephrol. Dial. Transplant. 24, 1524-1528. https://doi.org/10.1093/ndt/gfn677 (2009).

6. van Paassen, P., van Breda Vriesman, P. J., van Rie, H. \& Tervaert, J. W. Signs and symptoms of thin basement membrane nephropathy: A prospective regional study on primary glomerular disease-The Limburg Renal Registry. Kidney Int. 66, 909-913. https://doi.org/10.1111/j.1523-1755.2004.00835.x (2004).

7. Braun, N. et al. Epidemiology of glomerulonephritis in Northern Germany. Int. Urol. Nephrol. 43, 1117-1126. https://doi.org/ 10.1007/s11255-011-9955-4 (2011). 
8. Kurnatowska, I. et al. Trends in the incidence of biopsy-proven glomerular diseases in the adult population in central Poland in the years 1990-2010. Kidney Blood Press Res. 35, 254-258. https://doi.org/10.1159/000334418 (2012).

9. Maixnerova, D. et al. Nationwide biopsy survey of renal diseases in the Czech Republic during the years 1994-2011. J. Nephrol. 28, 39-49. https://doi.org/10.1007/s40620-014-0090-z (2015).

10. Menyhárt, O., Fekete, J. T. \& Győrffy, B. Demographic shift disproportionately increases cancer burden in an aging nation: Current and expected incidence and mortality in Hungary up to 2030. Clin. Epidemiol. 10, 1093-1108. https://doi.org/10.2147/ clep.S155063 (2018).

11. Organisation for Economic Co-operation and Development, E. O. o. H. S. \& Policies. Hungary: Country Health Profile (2019).

12. Monga, D. \& Jhaveri, K. D. Glomerular diseases and cancer. in Onco-Nephrology Curriculum. https://www.asn-online.org/educa tion/distancelearning/curricula/onco/Chapter6.pdf (American Society of Nephrology, 2016).

13. Bidani, A. K. \& Griffin, K. A. Pathophysiology of hypertensive renal damage: Implications for therapy. Hypertension 44, 595-601. https://doi.org/10.1161/01.HYP.0000145180.38707.84 (2004).

14. Lim, A. K. Diabetic nephropathy-Complications and treatment. Int. J. Nephrol. Renov. Dis. 7, 361-381. https://doi.org/10.2147/ IJNRD.S40172 (2014)

15. OECD, Systems, E. O. o. H. \& Policies. Hungary: Country Health Profile 2019 (2019).

16. Collaborators G. B. D. M. Global, regional, and national age-sex-specific mortality and life expectancy, 1950-2017: A systematic analysis for the Global Burden of Disease Study 2017. Lancet 392, 1684-1735. https://doi.org/10.1016/S0140-6736(18)31891-9 (2018).

17. Fiorentino, M. et al. Renal biopsy in 2015-From epidemiology to evidence-based indications. Am. J. Nephrol. 43, 1-19. https:// doi.org/10.1159/000444026 (2016).

18. Amodu, A., Porteny, T., Schmidt, I. M., Ladin, K. \& Waikar, S. S. Nephrologists' attitudes towards native kidney biopsy: A qualitative study. Kidney Med. https://doi.org/10.1016/j.xkme.2021.06.014 (2021).

19. Swaminathan, S. et al. Changing incidence of glomerular disease in Olmsted County, Minnesota: A 30-year renal biopsy study. Clin. J. Am. Soc. Nephrol. 1, 483-487. https://doi.org/10.2215/CJN.00710805 (2006).

20. Sugiyama, H. et al. Japan renal biopsy registry and Japan kidney disease registry: Committee report for 2009 and 2010. Clin. Exp. Nephrol. 17, 155-173. https://doi.org/10.1007/s10157-012-0746-8 (2013).

21. Li, L. S. \& Liu, Z. H. Epidemiologic data of renal diseases from a single unit in China: Analysis based on 13,519 renal biopsies. Kidney Int. 66, 920-923. https://doi.org/10.1111/j.1523-1755.2004.00837.x (2004).

22. Naumovic, R., Pavlovic, S., Stojkovic, D., Basta-Jovanovic, G. \& Nesic, V. Renal biopsy registry from a single centre in Serbia: 20 years of experience. Nephrol. Dial. Transplant. 24, 877-885. https://doi.org/10.1093/ndt/gfn564 (2009).

23. Polenakovic, M. H., Grcevska, L. \& Dzikova, S. The incidence of biopsy-proven primary glomerulonephritis in the Republic of Macedonia-long-term follow-up. Nephrol. Dial. Transplant. 18(Suppl 5), v26-v27. https://doi.org/10.1093/ndt/gfg1039 (2003).

24. Oygar, D. D. \& Neild, G. H. Reporting renal biopsies from Cyprus: A systematic approach. J. Nephropathol. 6, 231-239. https:// doi.org/10.15171/jnp.2017.38 (2017).

25. Ahmad, M. Y. et al. 6th Report of the Malaysian Registry OS Renal Biopsy (Malaysian Society of Nephrology, 2017).

26. Ben Maiz, H., Abderrahim, E., Ben Moussa, F., Goucha, R. \& Karoui, C. Epidemiology of glomerular diseases in Tunisia from 1975 to 2005. Influence of changes in healthcare and society. Bull. Acad. Natl. Med. 190, 403-416 (2006) (discussion 416-408).

27. Barsoum, R. S. \& Francis, M. R. Spectrum of glomerulonephritis in egypt. Saudi J. Kidney Dis. Transpl. 11, 421-429 (2000).

28. McLigeyo, S. O. Gromerular diseases in Kenya-Another look at diseases characterised by nephrotic proteinura. Afr. J. Health Sci. 1, 185-190 (1994).

29. Turkmen, A. et al. Epidemiological features of primary glomerular disease in Turkey: A multicenter study by the Turkish Society of Nephrology Glomerular Diseases Working Group. BMC Nephrol. 21, 481. https://doi.org/10.1186/s12882-020-02134-8 (2020).

30. Jegatheesan, D. et al. Epidemiology of biopsy-proven glomerulonephritis in Queensland adults. Nephrology (Carlton) 21, 28-34. https://doi.org/10.1111/nep.12559 (2016).

31. Hizon, M. A. P. et al. Sun-014 epidemiology of glomerulonephritis in Southeast Asia: The GN-special (glomerulonephritisSingapore-Philippines epidemiology cohorts in adults) study. Kidney Int. Rep. 4, S158. https://doi.org/10.1016/j.ekir.2019.05. 408 (2019).

32. Nadium, W. K., Abdelwahab, H. H., Ibrahim, M. A. \& Shigidi, M. M. Histological pattern of primary glomerular diseases among adult Sudanese patients: A single center experience. Indian J. Nephrol. 23, 176-179. https://doi.org/10.4103/0971-4065.111838 (2013).

33. Chavez Valencia, V. et al. Epidemiology of glomerular disease in adults: A database review. Gac. Med. Mex. 150, 403-408 (2014).

34. Arias, L. F. et al. Glomerular diseases in a Hispanic population: Review of a regional renal biopsy database. Sao Paulo Med. J. 127, 140-144. https://doi.org/10.1590/s1516-31802009000300006 (2009).

35. Storch, S. et al. Kidney diseases in North Israel according to kidney biopsies-Bnai-Zion medical center 14 years' experience. Harefuah 155, 537-541 (2016).

36. Al Riyami, D., Al Shaaili, K., Al Bulushi, Y., Al Dhahli, A. \& Date, A. The spectrum of glomerular diseases on renal biopsy: Data from a single tertiary center in oman. Oman Med. J. 28, 213-215. https://doi.org/10.5001/omj.2013.58 (2013).

37. Mubarak, M. et al. Pattern of renal diseases observed in native renal biopsies in adults in a single centre in Pakistan. Nephrology (Carlton) 16, 87-92. https://doi.org/10.1111/j.1440-1797.2010.01410.x (2011).

38. Garyal, K. R. K. Hisopathological spectrum of glomerular disease in Nepal: A seven-year retrospective study. Nepal Med. Coll. J. 10, 126-128 (2008).

39. Islam, S. M. J., Haque, W. S., Akhter, S. \& Mahbubul Alam, S. M. Histomorphological pattern of renal biopsy in Dhaka: A single center study. Saudi J. Kidney Dis. Transpl. 29, 1159-1164. https://doi.org/10.4103/1319-2442.243940 (2018).

40. Bach, N., Huynh, L., Linh, H. T. \& Thang, D. Indications and histologic patterns of biopsy-proven kidney diseases in Vietnamese adult patients. J. Clin. Nephrol. Res. 3, 1052 (2016).

41. Santa Cruz, F., Cabrera, W., Barreto, S., Mayor, M. M. \& Baez, D. Kidney disease in Paraguay. Kidney Int. Suppl. https://doi.org/ 10.1111/j.1523-1755.2005.09720.x (2005).

42. Pakasa, M., Mangani, N. \& Dikassa, L. Focal and segmental glomerulosclerosis in nephrotic syndrome: A new profile of adult nephrotic syndrome in Zaire. Mod. Pathol. 6, 125-128 (1993).

43. Onwubuya, I. M., Adelusola, K. A., Sabageh, D., Ezike, K. N. \& Olaofe, O. O. Biopsy-proven renal disease in Ile-Ife, Nigeria: A histopathologic review. Indian J. Nephrol. 26, 16-22. https://doi.org/10.4103/0971-4065.155732 (2016).

44. Sipiczki, T. et al. The incidence of renal diseases as diagnosed by biopsy in Hungary. Orv. Hetil. 145, 1373-1379 (2004).

45. Légrády, P. B. A. et al. Overview of a 10 years kidney biopsies data from the nephrological and blodd pressure center szeged. Hypertonia és Nephrologia 2019, 115-123 (2019).

46. Wirta, O., Mustonen, J., Helin, H. \& Pasternack, A. Incidence of biopsy-proven glomerulonephritis. Nephrol. Dial. Transplant. 23, 193-200. https://doi.org/10.1093/ndt/gfm564 (2008).

47. Brazdziute, E. et al. Nationwide renal biopsy data in Lithuania 1994-2012. Int. Urol. Nephrol. 47, 655-662. https://doi.org/10. 1007/s11255-015-0927-y (2015).

48. Riispere, Z. \& Ots-Rosenberg, M. Occurrence of kidney diseases and patterns of glomerular disease based on a 10-year kidney biopsy material: A retrospective single-centre analysis in Estonia. Scand. J. Urol. Nephrol. 46, 389-394. https://doi.org/10.3109/ 00365599.2012.693133 (2012). 
49. Heaf, J. The Danish renal biopsy register. Kidney Int. 66, 895-897. https://doi.org/10.1111/j.1523-1755.2004.00832.x (2004).

50. Schena, F. P. Survey of the Italian registry of renal biopsies. Frequency of the renal diseases for 7 consecutive years. The Italian group of renal immunopathology. Nephrol. Dial. Transplant. 12, 418-426. https://doi.org/10.1093/ndt/12.3.418 (1997).

51. Rivera, F., Lopez-Gomez, J. M., Perez-Garcia, R., Spanish Registry of, G. Frequency of renal pathology in Spain 1994-1999. Nephrol. Dial. Transplant. 17, 1594-1602. https://doi.org/10.1093/ndt/17.9.1594 (2002).

52. Briganti, E. M. et al. The incidence of biopsy-proven glomerulonephritis in Australia. Nephrol. Dial. Transplant. 16, 1364-1367. https://doi.org/10.1093/ndt/16.7.1364 (2001).

53. Carvalho, E., do Sameiro Faria, M., Nunes, J. P., Sampaio, S. \& Valbuena, C. Renal diseases: A 27-year renal biopsy study. J. Nephrol. 19, 500-507 (2006).

54. Reisæter, A. e. a. The Norwegian Renal Registry, Annual Report 2018 (The Norwegian Renal Association, Oslo UniversityHospitalRikshospitalet, 2018).

55. Shcherbak, K. Epidemiology and Outcome of Glomerular Disease in Iceland: A Nationwide, Population-Based Study, 1983-2002 (University of Iceland, 2017)

56. Herdson, P. B., Ojeda, V. J. \& Teague, C. A. Renal biopsy pathology in Auckland, 1969-1976. N. Z. Med. J. 86, 5-6 (1977)

57. Horvatic, I. et al. Epidemiologic data of adult native biopsy-proven renal diseases in Croatia. Int. Urol. Nephrol. 45, 1577-1587. https://doi.org/10.1007/s11255-013-0397-z (2013).

58. Dobronravov, V., Muzhetskaya, T., Lin, D. \& Kochoyan, Z. Immunoglobulin A-nephropathy in Russian population: Clinical and morphological presentation and long-term prognosis. Nephrology (Saint-Petersburg) 23, 45-60. https://doi.org/10.36485/ 1561-6274-2019-236-45-60 (2019).

59. Naini, A. E., Harandi, A. A., Ossareh, S., Ghods, A. \& Bastani, B. Prevalence and clinical findings of biopsy-proven glomerulonephritidis in Iran. Saudi J. Kidney Dis. Transpl. 18, 556-564 (2007).

60. Jalalah, S. Changing frequency of glomerular diseases in Western Saudi Arabia: A 26-year experience. J. Microsc. Ultrastruct. 8, 89-95. https://doi.org/10.4103/jmau.Jmau_64_19 (2020).

61. Polito, M. G., de Moura, L. A. \& Kirsztajn, G. M. An overview on frequency of renal biopsy diagnosis in Brazil: Clinical and pathological patterns based on 9,617 native kidney biopsies. Nephrol. Dial. Transplant. 25, 490-496. https://doi.org/10.1093/ ndt/gfp355 (2010).

62. Mazzuchi, N. et al. Frequency of diagnosis and clinic presentation of glomerulopathies in Uruguay. Nefrologia 25, 113-120 (2005).

63. Cerdas, M. Chronic kidney disease in Costa Rica. Kidney Int. Suppl. https://doi.org/10.1111/j.1523-1755.2005.09705.x (2005).

64. Aatif, T., Maoujoud, O., Montasser, D. I., Benyahia, M. \& Oualim, Z. Glomerular diseases in the Military Hospital of Morocco: Review of a single centre renal biopsy database on adults. Indian J. Nephrol. 22, 257-263. https://doi.org/10.4103/0971-4065. 101244 (2012).

65. Al Arrayed, A., Shariff, S. \& Al Maamari, M. Kidney disease in Bahrain: A biopsy based epidemiologic study. Saudi J. Kidney Dis. Transplant. 18, 638-642 (2007).

66. Choi, I. J. et al. An analysis of 4,514 cases of renal biopsy in Korea. Yonsei Med. J. 42, 247-254. https://doi.org/10.3349/ymj.2001. 42.2.247 (2001)

67. Albaar, A. et al. Sun-391 histopathology pattern of renal biopsy in nephrotic syndrome patients: A single centre study in Hasanuddin University Teaching Hospital, Makassar, South Sulawesi, Indonesia. Kidney Int. Rep. 5, S360-S361. https://doi.org/10. 1016/j.ekir.2020.02.931 (2020).

68. Barbour, S. et al. An overview of the British Columbia Glomerulonephritis network and registry: Integrating knowledge generation and translation within a single framework. BMC Nephrol. 14, 236. https://doi.org/10.1186/1471-2369-14-236 (2013).

69. Mbakop, A., Youmbissi, T. J., Gonsu, J. D., Chatelanat, F. \& Ngu, J. L. Renal puncture biopsy in nephrotic syndrome in Cameroonian children, adolescent and adults: Histopathologic profile according to age. Arch. Anat. Cytol. Pathol. 38, 104-107 (1990).

70. Das, U., Dakshinamurty, K. V. \& Prayaga, A. Pattern of biopsy-proven renal disease in a single center of south India: 19 years experience. Indian J. Nephrol. 21, 250-257. https://doi.org/10.4103/0971-4065.85482 (2011).

71. Covic, A. et al. Epidemiology of renal disease in Romania: A 10 year review of two regional renal biopsy databases. Nephrol. Dial. Transplant. 21, 419-424. https://doi.org/10.1093/ndt/gfi207 (2006).

72. Borok, M. Z., Nathoo, K. J., Gabriel, R. \& Porter, K. A. Clinicopathological features of Zimbabwean patients with sustained proteinuria. Cent. Afr. J. Med. 43, 152-158 (1997).

73. Niang, A. et al. Nephrotic syndrom with focal and segmental glomerulosclerosis in Dakar: Epidemiological and clinicopathological characteristics (about 134 cases). Dakar Med. 53, 45-51 (2008).

74. Yahya, T., Pingle, A., Boobes, Y. \& Pingle, S. Analysis of 490 kidney biopsies: Data from the United Arab Emirates renal diseases registry. J. Nephrol. 11(3), 148-150 (1998).

75. Hurtado, A. et al. Distinct patterns of glomerular disease in Lima, Peru. Clin. Nephrol. 53, 325-332 (2000).

76. Okpechi, I. et al. Patterns of renal disease in Cape Town South Africa: A 10-year review of a single-centre renal biopsy database. Nephrol. Dial. Transplant. 26, 1853-1861. https://doi.org/10.1093/ndt/gfq655 (2011).

77. Parichatikanond, P. et al. An analysis of 3,555 cases of renal biopsy in Thailand. J. Med. Assoc. Thai 89(Suppl 2), S106-S111 (2006).

78. Sarishvili, N. et al. MO312MAIN trends and outcomes of kidney disease in Georgia: The first review of kidney biopsy database from 2011 to 2020. Nephrol. Dial. Transplant. https://doi.org/10.1093/ndt/gfab104.0070 (2021).

79. Visconti, L. et al. Renal biopsy: Still a landmark for the nephrologist. World J. Nephrol. 5, 321-327. https://doi.org/10.5527/wjn. v5.i4.321 (2016).

80. Rovin, B. H. et al. KDIGO 2021 clinical practice guideline for the management of glomerular diseases. Kidney Int. 100, S1-S276. https://doi.org/10.1016/j.kint.2021.05.021 (2021).

81. Ungvari, Z. et al. Hypertension-induced cognitive impairment: From pathophysiology to public health. Nat. Rev. Nephrol. https:// doi.org/10.1038/s41581-021-00430-6 (2021).

82. Guillevin, L. et al. Microscopic polyangiitis: Clinical and laboratory findings in eighty-five patients. Arthritis Rheum. 42, 421-430. https://doi.org/10.1002/1529-0131(199904)42:3\%3c421::AID-ANR5\%3e3.0.CO;2-6 (1999).

83. Ramos, R. et al. Renal involvement in benign monoclonal gammopathies: An underdiagnosed condition. Nefrologia 28, 525-529 (2008).

84. Nasr, S. H. et al. Proliferative glomerulonephritis with monoclonal IgG deposits. J. Am. Soc. Nephrol. 20, 2055-2064. https:// doi.org/10.1681/ASN.2009010110 (2009).

85. Larsen, C. P. et al. Membranoproliferative glomerulonephritis with masked monotypic immunoglobulin deposits. Kidney Int. 88, 867-873. https://doi.org/10.1038/ki.2015.195 (2015).

86. Sethi, S. \& Rajkumar, S. V. Monoclonal gammopathy-associated proliferative glomerulonephritis. Mayo Clin. Proc. 88, 1284-1293. https://doi.org/10.1016/j.mayocp.2013.08.002 (2013).

87. White, M. C. et al. Age and cancer risk: A potentially modifiable relationship. Am. J. Prev. Med. 46, S7-S15. https://doi.org/10. 1016/j.amepre.2013.10.029 (2014).

88. Deegens, J. K. \& Wetzels, J. F. Membranous nephropathy in the older adult: Epidemiology, diagnosis and management. Drugs Aging 24, 717-732. https://doi.org/10.2165/00002512-200724090-00002 (2007). 
89. Couser, W. G. Primary membranous nephropathy. Clin. J. Am. Soc. Nephrol. 12, 983-997. https://doi.org/10.2215/CJN.11761 116 (2017).

90. Bray, F. et al. Global cancer statistics 2018: GLOBOCAN estimates of incidence and mortality worldwide for 36 cancers in 185 countries. CA Cancer J. Clin. 68, 394-424. https://doi.org/10.3322/caac.21492 (2018).

91. White, A. et al. A review of sex-related differences in colorectal cancer incidence, screening uptake, routes to diagnosis, cancer stage and survival in the UK. BMC Cancer 18, 906. https://doi.org/10.1186/s12885-018-4786-7 (2018).

92. Lerner, G. B., Virmani, S., Henderson, J. M., Francis, J. M. \& Beck, L. H. A conceptual framework linking immunology, pathology, and clinical features in primary membranous nephropathy. Kidney Int. https://doi.org/10.1016/j.kint.2021.03.028 (2021).

93. Quinn, G. et al. Renal histologic analysis provides complementary information to kidney function measurement for patients with early diabetic or hypertensive disease. J. Am. Soc. Nephrol. https://doi.org/10.1681/asn.2021010044 (2021).

94. Kitching, A. R. et al. ANCA-associated vasculitis. Nat. Rev. Dis. Primers 6, 71. https://doi.org/10.1038/s41572-020-0204-y (2020).

95. Shi, J., Shen, Q., Chen, X. M. \& Du, X. G. Clinical characteristics and outcomes in microscopic polyangiitis patients with renal involvement: A study of 124 Chinese patients. BMC Nephrol. 20,339. https://doi.org/10.1186/s12882-019-1535-3 (2019).

96. Flossmann, O. et al. Long-term patient survival in ANCA-associated vasculitis. Ann. Rheum. Dis. 70, 488-494. https://doi.org/ 10.1136/ard.2010.137778 (2011).

97. Agard, C., Mouthon, L., Mahr, A. \& Guillevin, L. Microscopic polyangiitis and polyarteritis nodosa: How and when do they start?. Arthritis Rheum. 49, 709-715. https://doi.org/10.1002/art.11387 (2003).

98. Mohammad, A. J. An update on the epidemiology of ANCA-associated vasculitis. Rheumatology (Oxford) 59, iii42-iii50. https:// doi.org/10.1093/rheumatology/keaa089 (2020).

99. Gibson, A., Stamp, L. K., Chapman, P. T. \& O’Donnell, J. L. The epidemiology of Wegener's granulomatosis and microscopic polyangiitis in a Southern Hemisphere region. Rheumatology (Oxford) 45, 624-628. https://doi.org/10.1093/rheumatology/ kei259 (2006).

100. Watts, R. A., Lane, S. E., Bentham, G. \& Scott, D. G. Epidemiology of systemic vasculitis: A ten-year study in the United Kingdom. Arthritis Rheum. 43, 414-419. https://doi.org/10.1002/1529-0131(200002)43:2\%3c414::Aid-anr23\%3e3.0.Co;2-0 (2000).

101. Mohammad, A. J., Jacobsson, L. T., Westman, K. W., Sturfelt, G. \& Segelmark, M. Incidence and survival rates in Wegener's granulomatosis, microscopic polyangiitis, Churg-Strauss syndrome and polyarteritis nodosa. Rheumatology (Oxford) 48, 1560-1565. https://doi.org/10.1093/rheumatology/kep304 (2009).

102. Chen, K. R. Skin involvement in ANCA-associated vasculitis. Clin. Exp. Nephrol. 17, 676-682. https://doi.org/10.1007/s10157012-0736-x (2013).

103. Cornec, D., Cornec-Le Gall, E., Fervenza, F. C. \& Specks, U. ANCA-associated vasculitis-Clinical utility of using ANCA specificity to classify patients. Nat. Rev. Rheumatol. 12, 570-579. https://doi.org/10.1038/nrrheum.2016.123 (2016).

104. Bazina, M. et al. Epidemiology of renal disease in children in the region of southern Croatia: A 10-year review of regional renal biopsy databases. Med. Sci. Monit. 13, CR172-CR176 (2007).

105. Tomson, C. R. V. Primary Renal Disease (PRD) codes; ERA-EDTA registry (University of Amsterdam, 2018).

\section{Acknowledgements}

We would like to thank all the patients who underwent the intervention and all the physicians who performed the renal biopsies. The biopsies were performed in 25 hospitals; the following five hospitals performed the most: Semmelweis University Budapest Department of Internal Medicine and Oncology, Semmelweis University Budapest First Department of Pediatrics, Petz Aladár Hospital Győr, Szent Imre University Hospital Budapest, Uzsoki Hospital Budapest.

\section{Author contributions}

A.M. and A.F. reviewed and corrected the diagnostic categories. A.M. and M.K. digitalized the data. A.M. created the database used for the analysis. A.F., M.K. and D.D. performed the histopathological assessment. A.M., M.J.T. and N.L. performed the statistical analysis. A.M., A.T. and N.L. made the concept of the report. A.M. and N.L. interpreted the data and drafted the manuscript. All authors revised the manuscript and approved the final version to be published and agree to be accountable for all aspects of the work.

\section{Funding}

Open Access funding provided by Semmelweis University.

\section{Competing interests}

The authors declare no competing interests.

\section{Additional information}

Supplementary Information The online version contains supplementary material available at https://doi.org/ 10.1038/s41598-021-04274-9.

Correspondence and requests for materials should be addressed to N.L.

Reprints and permissions information is available at www.nature.com/reprints.

Publisher's note Springer Nature remains neutral with regard to jurisdictional claims in published maps and institutional affiliations. 
(c) (i) Open Access This article is licensed under a Creative Commons Attribution 4.0 International cc) License, which permits use, sharing, adaptation, distribution and reproduction in any medium or format, as long as you give appropriate credit to the original author(s) and the source, provide a link to the Creative Commons licence, and indicate if changes were made. The images or other third party material in this article are included in the article's Creative Commons licence, unless indicated otherwise in a credit line to the material. If material is not included in the article's Creative Commons licence and your intended use is not permitted by statutory regulation or exceeds the permitted use, you will need to obtain permission directly from the copyright holder. To view a copy of this licence, visit http://creativecommons.org/licenses/by/4.0/.

(C) The Author(s) 2021 